\title{
Expectations and perception of the psychotherapy process and outcome. Psychotherapeutic factors and the psychodrama specificities in psychodrama group participants at a psychiatric hospital
}

\author{
Tihana Jendričko $\cdot$ Simona Prosen
}

(C) Springer Fachmedien Wiesbaden GmbH, ein Teil von Springer Nature 2020

\begin{abstract}
In the present article of the Zeitschrift für Psychodrama und Soziometrie, the expectations (self-assessed at the beginning of the treatment) and perception (self-assessed upon the conclusion of the treatment) of the psychotherapy process and outcome, psychotherapeutic factors and psychodrama specificities are presented and analysed in a psychodrama group for adult participants held in an outpatient psychiatric clinic. There were 12 male and 31 female participants, aged from 19 to 63 years, diagnosed with anxiety, depression, and borderline personality disorder or committed into the hospital after their first psychotic episode. Questionnaires were applied at the beginning of the treatment and at the end. Results showed that the participants' expectations regarding the psychotherapy process and outcomes were quite high at the beginning of the treatment and rose significantly at the end. The same was true of the participants' expectations and perception of the specificities of psychodrama-demonstrating the participants' positive inclination towards this specific psychotherapeutic way of conducting psychodrama. Even though there were no age or gender differences, there were, differences between participants' different diagnoses; there were significant differences in the expectations of both psychotherapy outcome and factors before treatment and perceptions of them after treatment.
\end{abstract}

Keywords Psychodrama P Psychotherapy · Adult outpatients - Age differences · Gender differences $\cdot$ Diagnosis differences

T. Jendričko, M.D., PhD (ه)

University Psychiatric Hospital Vrapče, Bolnička cesta 32, 10000 Zagreb, Croatia

E-Mail: tihana.jendricko@bolnica-vrapce.hr

S. Prosen, $\mathrm{PhD}$

Faculty of Education University of Ljubljana, Kardeljeva pl. 16, 1000 Ljubljana, Slovenia

E-Mail: simona.prosen@pef.uni-lj.si 


\section{Erwartungen und Wahrnehmungen bezüglich des psychotherapeutischen Prozesses und Effektes. Psychotherapeutische Faktoren und Psychodramaspezifitäten von TeilnehmerInnen einer Psychodramagruppe in einer psychiatrischen Klinik}

Zusammenfassung In dem vorliegenden Artikel der Zeitschrift für Psychodrama und Soziometrie werden Erwartungen und Wahrnehmungen des Psychotherapieprozesses und der Effekte sowie psychotherapeutische Faktoren und Psychodramaspezifitäten in der Psychodramagruppe für erwachsene Teilnehmer einer ambulanten psychiatrischen Klinik vorgestellt und analysiert. Es gab 12 männliche und 31 weibliche TeilnehmerInnen im Alter von 19 bis 63 Jahren, bei denen Angstzustände, Depressionen, Borderline-Persönlichkeitsstörungen diagnostiziert wurden oder die nach ihrer ersten psychotischen Episode ins Krankenhaus eingeliefert wurden. Die Fragebögen wurden zu Beginn und am Ende der Behandlung angewendet. Die Ergebnisse zeigen, dass die Erwartungen der TeilnehmerInnen an dem Psychotherapieprozess und den Effekten zu Beginn der Behandlung recht hoch sind und am Ende sogar deutlich steigen. Gleiches gilt für die Erwartungen und Wahrnehmungen von Psychodramaspezifitäten durch die TeilnehmerInnen - möglicherweise zeigt dies die positive Neigung der TeilnehmerInnen zur spezifischen Art und Weise, einen psychotherapeutischen Prozess im Psychodrama durchzuführen. Obwohl es keine Alters- oder Geschlechtsunterschiede gibt, gab es zwischen TeilnehmerInnen mit unterschiedlichen Diagnosen signifikante Unterschiede in den Erwartungen an das Psychotherapieergebnis vor und nach der Behandlung sowie in der Erwartung hinsichtlich psychotherapeutischer Faktoren vor der Behandlung.

Schlüsselwörter Psychodrama P Psychotherapie $\cdot$ Erwachsene tagklinische PatientInnen · Altersunterschiede $\cdot$ Geschlechtsunterschiede $\cdot$ Diagnoseunterschiede

\section{Introduction}

\subsection{Psychodrama}

Psychodrama is a psychotherapy approach that uses sociometry, role theory and group dynamics in order to enable an individual to gain insight into their own thoughts, including their emotional and behavioural processes regarding the self and others. It takes place in a safe group environment and utilizes the spontaneity and creativity of both the individual and the group (Dayton 1994). A psychodrama session usually consists of three components: a warm-up, a psychodrama action with a protagonist (a person whose theme is being explored in a psychodramatic way, by using different psychodrama techniques such as role reversal, mirroring and including other group participants to play different roles) and sharing, during which each group member has the opportunity to share their emotions, thoughts and insights during psychodrama. Psychodrama psychotherapy presents an opportunity for a corrective experience, sometimes by integrating a (painful) past experience, sometimes in creating a missing experience (Prosen 2016). 
Psychodrama has certain specificities, which include its emphasis on encouraging spontaneity and creativity, employing role-playing and thus increasing flexibility in existing roles and the development of new roles. Role-playing also provides for insights into one's own problems and represents an active approach to therapy, as opposed to a solely verbal way of conducting therapy. These specificities will be explored further in this article.

Spontaneity is a precondition for successful role-playing and allows us to react in a new way to an already familiar situation. It is also a prerequisite for developing and expressing creativity (Blatner 2000, 2007). Moreno (1983) described a "canon of creativity" in a diagram that showed the relationship between spontaneity and creativity: starting with what has already been created, the group (or person) can warm up to a state of spontaneity out of which new creativity flows.

Role-play is the recognisable way of practicing therapy in psychodrama. Many roles can be created, named and developed through the process of psychodrama, or personal development. However, people do not have to accept their present role repertoire. On the contrary, creating roles makes a bridge between surplus reality and ordinary life (Blatner 2000). During psychodrama many insights may take place, especially since psychodrama is based on the appreciation of an individual's need for self-expression. Talking is better than not talking, but acting, moving and adding other modalities makes the experience even more fulfilling. These may lead to both clarification and validation of feelings and ideas as "they are brought into explicit consciousness, from backstage to centre stage, into the figurative spotlight of awareness" (Baars 1997, in Blatner 2000, p. 100). Adding action to verbal self-expression was inhibited by its confusion with unmodulated or non-reflective "actingout" (Rexford 1978, in Blatner 2000, p. 101). However, psychodrama is designed to use these energies so that what happens is not counter-therapeutic, but rather in the service of insight (Blatner 1973, in Blatner 2000).

\subsection{Therapeutic alliance; Therapy process and outcome expectations}

The outcome of a psychotherapeutic process is often influenced by so-called nonspecific factors (Ardito and Rabellino 2011; Strupp 2001; Strupp and Hadley 1979), namely the personal characteristics of the therapist and the positive feelings that arise in the client. These feelings can lead to the creation of a positive therapeutic climate from an emotional and interpersonal perspective. This emotional bond between therapist and client is also known as the therapeutic alliance.

Horvath and Luborsky (1993) considered that the concept of the therapeutic alliance originates from Freud's theory of transference. At first Freud (1913) was negative, but in his later works he adopted a different stance on the issue of transference and considered the possibility of a beneficial attachment actually developing between therapist and client, and not as a projection. Such attachment was an important component in Roger's interpretation of therapeutic alliance. He saw congruence, empathy and unconditional positive regard as the main components of this alliance. These were seen as the core conditions offered by the therapist, but were later shown to be specifically essential for client-centred therapy (Ardito and Rabellino 2011; Horvath and Greenberg 1989; Horvath and Luborsky 1993). 
Luborsky (1976) distinguished two types of alliance: the first, found in the early phases of therapy, was based on the client's perception of the therapist as a supportive character, and the second, more typical of later phases in therapy, represented the collaborative relationship between client and therapist to overcome the client's problems. Whereby they share responsibility in working to achieve the goals of therapy in a sense of communion.

The definition for therapeutic alliance proposed by Bordin (1979) also underlines the collaborative relationship between client and therapist in the common fight to overcome the client's suffering and self-destructive behaviour. According to him, the therapeutic alliance consists of three essential elements: an agreement on the goals of the treatment, an agreement on the tasks and the development of a personal bond made up of reciprocal positive feelings.

Some studies have examined the relationship between alliance and outcome in group psychotherapy. Compared to an individual therapeutic setting, the main difference is that in group psychotherapy multiple therapeutic agents are present: the therapist (usually two co-therapists), members of the group and the group as a whole. One conceptualisation of therapeutic alliance in group psychotherapy follows Bordin's theory, transferring a multifactorial construct from an individual to a group setting (Zilcha-Mano et al. 2019). Also, Pinsof and Catherall (1986) adapted Bordin's model to multiple interpersonal subsystems. These subsystems involve selfto-therapist alliance, group-to-therapist alliance, self-to-members alliance and otherto-therapist alliance. From this point of view, an alliance can be conceived as the totality of the alliances formed (Gillaspy et al. 2002).

Sometimes, impairment or fluctuation in the quality of the alliance between therapist and client can cause an alliance rupture (Safran and McMain 1990). Depending on the relationship, alliance ruptures may vary in intensity, duration and frequency. In more extreme cases, the client may overtly indicate negative sentiments to the therapist or even terminate therapy prematurely. At the other end of the continuum, there are minor fluctuations in the quality of the therapeutic alliance, which may be extremely difficult for the outside observer or even for the skilled therapist to detect. While the features of alliance ruptures vary from case to case, most therapy cases, even the more successful ones, are characterized by at least one or more ruptures in the therapeutic alliance over the course of therapy. One of the factors connected to the therapeutic alliance are the client expectations for the psychotherapy process and outcome (e.g., Glass et al. 2001, in Norberg et al. 2011). Expectations about the psychotherapy process include the client's beliefs about what will happen during therapy, what qualities the therapist will have, how will the therapy be structured, how long it will last, how the change will take place and what will the therapist-client relationship look like. Outcome expectations include the client's beliefs regarding their improvement: about the potential ways in which client's characteristics may change with the help of therapy (Norberg et al. 2011). Lambert and Barley (2001) estimated that $15 \%$ of variance in psychotherapy outcomes is due to the expectancy effect. The expectations have an impact on the therapeutic process in multiple ways. For example, they are connected to the persistence or drop out from therapy (D'Aniello and Tambling 2017). 


\subsection{Yalom's group therapeutic factors}

Yalom and Leszcz (2005, p. 13) defined therapeutic factors as "the actual mechanisms of effecting change in the patient". They influence the processes of change and recovery among group therapy clients. According to Yalom and Leszcz (2005, p. 22), based on the "intricate interplay of human experience" that are present in all group interventions and represent a pathway to therapeutic change, eleven therapeutic factors were identified.

They are: instillation of hope (encouragement that recovery is possible), universality (the feeling of having problems similar to others, not being alone), imparting information (teaching about the problem and recovery), altruism (helping and supporting others), corrective recapitulation of the primary family group (identifying and changing the dysfunctional patterns or roles one played in the primary family), development of socialising techniques (learning new ways to talk about feelings, observations and concerns), imitative behaviours (modelling another's manners and recovery skills), interpersonal learning (finding out about themselves and others from the group), group cohesiveness (feeling of belonging to the group, valuing the group), catharsis (release of emotional tension), and existential factors (life and death are realities).

It has been suggested that what is therapeutic in a given group may vary depending on the client's cultural factors (DeLucia-Waack 1996) or age (McLeod and Ryan 1993) and that, within a group, cultural differences may mediate the therapist's ability to foster therapeutic factors (Johnson et al. 1995). Treatment setting (Fuhriman et al. 1986), group format (Goldberg et al. 1988; Kellerman 1987) and time-limits (Flowers 1987; Marcovitz and Smith 1983) may also cause variations in the influence of therapeutic factors. Furthermore, the stage of group development affects the significance of therapeutic factors (Yalom and Leszcz 2005) and how interventions work (Clark 1993).

Given this conceptual understanding, it makes sense that the therapist's ability to target different therapeutic factors, for different presenting problems, cultural groups or stages of group development, could improve the effectiveness of any given group (Crouch et al. 1994). However, without reliable and valid methods of assessing the factors it is difficult to direct interventions to therapeutic factors within specific groups.

The aim of our study, which is conducted in a psychotherapy context, was to try to 'capture' the expectations and perception of the psychotherapy process and outcome, psychotherapeutic factors and the psychodrama specifcs with adult participants of a psychodrama group at an outpatient psychiatric clinic, at the beginning and the end of psychotherapy treatment. This comparison may prove useful as an evaluation of psychodrama psychotherapy and may generate possible ideas for its further improvement. 


\section{Subjects and methods}

\subsection{Subjects}

All the participants attended an outpatient hospital programme at the University Psychiatric Hospital Vrapče in Zagreb, Croatia. The study was conducted with 43 participants, 12 male and 31 female, aged between 19 and $63(\mathrm{M}=40.44$ years, $\mathrm{SD}=12.46$ years). Among them, 23 were in young and 20 in middle adulthood according to developmental psychology criteria (Kail and Cavanaugh 2010; Zupančič et al. 2014). There were 18 participants diagnosed with anxiety disorder, 17 with depression, six with borderline personality disorder and two who had just experienced their first psychotic episode. They were receiving one or a combination of the following drugs: antidepressants, anxiolytics, antipsychotics or mood stabilizers. Among the 43 participants, 41 attended the 12-week programme for its entire duration, one stopped after eight weeks and another one after ten weeks. This was the first hospitalisation for 26 of them, and the second for the remaining 17 (with no previous experience of psychodrama). The programme they attended included an hour-long psychodrama group session once a week. Participants were included in this group after an interview with the leader of the group, who assessed their ability to participate in group psychotherapy. The group was led by a psychiatrist, who is also an experienced psychodrama psychotherapist.

Members of the group also underwent psychoeducation, reality therapy, work and occupational therapy as well as supportive therapy, which all contributed to the participants' sense of group membership.

\subsection{Measures}

The Milwaukee Psychotherapy Expectations Questionnaire (Norberg et al. 2011) was used to assess the participants' psychotherapy expectations and perception (at the beginning of the treatment) and perception (upon the conclusion of the treatment). It comprises of Process expectations/perceptions (relationship with the therapist) and Outcome expectations/perceptions. Process expectations are assessed by nine items, e.g. "I will feel comfortable with my therapist." Outcome expectations are assessed by four items, for example "After therapy, I will be a much more optimistic person." Participants indicate the degree to which they agree with each item on a 10-point Likert-type scale ranging from 1-not at all and somewhat to 10-very much so.

Based on Yalom's (Yalom and Leszcz 2005) list of group therapeutic factors, expectations and the perception of the group therapeutic factors were assessed via items describing expectations/perceptions regarding the group. There were six items, each assessed on a 10-point Likert-type scale ranging from 1-not at all and somewhat to 10-very much so. The items included the following therapeutic factors: universality ("I will find others who have a similar experience in the group"), interpersonal learning - input ("I will learn from others in the group") and interpersonal learning-output ("Others in the group will learn from me"), corrective recapitulation of the primary family group ("In therapy I will work on my early experiences"), development of socialising techniques ("In therapy I will get a better insight"), in- 
stillation of hope and existential factors ("I will gain faith in the future and find purpose in therapy").

The Psychodrama Specificities Questionnaire (Prosen and Jendričko 2014) was used to assess the participants' expectations and perception of certain specificities of the psychodramatic approach. There were six items describing expectations/ perceptions regarding the influence of the psychodrama group on a person's spontaneity, creativity, flexibility in existing roles, development of new roles, insight into their own problems, and efficiency of role-playing (vs. "only talking about it"). Again, each item was assessed on a 10-point Likert-type scale ranging from 1-not at all and somewhat to 10—very much so.

\subsection{Procedure and data analysis}

All of the psychodrama psychotherapy group participants, at the outpatient clinic of the University Psychiatric Hospital Vrapče in Zagreb Croatia, were invited to take part in the study. Their participation was voluntary and based on detailed information about the study that was presented to them both orally and in the form of a written consent that each participant signed prior to their involvement. Those willing to participate filled out the chosen questionnaires. Among them were questionnaires on therapy process and outcomes, therapeutic factors and psychodrama specificities. This was done at the beginning of their treatment in the outpatient clinic and at the end of the programme.

For the purposes of this article, the participants' self-assessment of their expectations and perception of the therapy process and outcome, therapeutic factors and psychodrama specificities were analysed. Normality of distribution was tested for each item in all three questionnaires. Since normality was not confirmed (ShapiroWilk tests and Kolmogorov-Smirnov tests, the majority of $\mathrm{p}_{\mathrm{s}}<0.00$ ), non-parametric statistical procedures were applied. Medians were calculated for each assessment (before and after treatment) and for each measure: process and outcome psychotherapeutic expectations/perception, therapeutic factors and psychodrama factors. Then, the Wilcoxon, Kruskal-Wallis or Mann-Whitney U tests were applied to establish possible differences between assessments as well as differences regarding the participants' gender, age or diagnoses. Finally, an analysis of intergroup variability regarding five psychodrama specificities (encouragement of spontaneity, encouragement of creativity, changes in old roles and the development of new ones, insight, playing the scenes instead of just verbally describing them) was performed.

\section{Results and interpretation}

\subsection{Group participants' expectation and perception of the psychotherapeutic process and outcome, psychotherapeutic factors and psychodrama specificities before and after treatment}

Firstly, medians are presented for each assessment (before and after treatment) for the psychotherapeutic process and outcome, psychotherapeutic factors and psychodrama 
Table 1 Medians and differences in expectations and perception of the psychotherapy process and outcome, psychotherapeutic factors and psychodrama specificities before and after treatment

\begin{tabular}{|c|c|c|c|c|c|}
\hline & $\begin{array}{l}\text { Assessment } 1 \\
\mathrm{Me}\end{array}$ & $\begin{array}{l}\text { Assessment } 2 \\
\mathrm{Me}\end{array}$ & $\begin{array}{l}\text { Related Sam- } \\
\text { ples Wilcoxon } \\
\text { Signed-Rank Test }\end{array}$ & $\begin{array}{l}\text { Mean } \\
\text { Rank }\end{array}$ & $\begin{array}{l}\text { Sum of } \\
\text { Ranks }\end{array}$ \\
\hline $\begin{array}{l}\text { Treatment expecta- } \\
\text { tions-Process }\end{array}$ & 9.00 & 9.67 & $\begin{array}{l}Z^{*}=-5.294 \\
p=0.000 \\
\mathrm{~A} 1<\mathrm{A} 2\end{array}$ & 5.50 & 16.50 \\
\hline $\begin{array}{l}\text { Treatment expecta- } \\
\text { tions-Outcome }\end{array}$ & 7.25 & 8.00 & $\begin{array}{l}\mathrm{Z}=-2.297 \\
p=0.022 \\
\mathrm{~A} 1<\mathrm{A} 2\end{array}$ & 21.25 & 212.50 \\
\hline $\begin{array}{l}\text { Yalom's group } \\
\text { factors }\end{array}$ & 7.67 & 8.00 & $\begin{array}{l}\mathrm{Z}=-1.948 \\
p=0.051 \\
\mathrm{~A} 1=\mathrm{A} 2\end{array}$ & 17.12 & 222.50 \\
\hline $\begin{array}{l}\text { Psychodrama } \\
\text { specificities }\end{array}$ & 7.17 & 7.83 & $\begin{array}{l}\mathrm{Z}=-3.022 \\
p=0.003 \\
\mathrm{~A} 1<\mathrm{A} 2\end{array}$ & 21.00 & 210.00 \\
\hline
\end{tabular}

Notes: $N=43 ; \mathrm{Me}=$ median; $* \mathrm{Z}$ is based on negative ranks; $1=$ assessment before treatment $2=$ assessment after treatment

specificities. Also, differences between the assessments (calculated using related samples non-parametric Wilcoxon Signed-Rank Test) are presented in Table 1.

When looking at the results, it can be noted that the group participants' expectations regarding their psychotherapy process and outcomes are quite high at the beginning of their treatment and significantly rise at the end. Their expectations regarding the psychotherapy process, which describes their relationship with the therapist are even higher. It is possible that such high expectations at the beginning of treatment imply the participants' inclination towards the establishment of a therapeutic alliance, an emotional bond between therapist and client (Strupp 2001; Strupp and Hadley 1979) or, according to Bordin (1979), a collaborative relationship between client and therapist that influences the outcome of a psychotherapeutic process. The fact that the participants' perceptions are even higher at the end of treatment may indicate that those high expectations were met in the course of treatment, resulting in therapeutic alliance: the agreement on the goals of the treatment, agreement on the tasks and the development of a personal bond made up of reciprocal positive feelings (Bordin 1979). Furthermore, it may indicate a shared responsibility for the goals of therapy and a sense of communion found in later phases of therapy (Luborsky 1976). The fact that therapy was carried out in a group setting should also be noted: the high perceptions regarding the therapeutic process and outcomes at the end of the treatment could be a sign of therapeutic alliance including not only the therapist-client relationship but also the totality of the alliances formed within a group (Gillaspy et al. 2002).

Furthermore, from the results, it can be noted that the group participants' expectations regarding psychotherapeutic factors are also quite high from the beginning of their treatment, and at its end. Again, these results may imply the participants' positive inclination towards the chosen group therapeutic factors that represent a pathway to therapeutic change (Yalom and Leszcz 2005). 
Finally, the results show that the group participants' expectations of psychodrama specificities are also quite high from the beginning of their treatment and they significantly increase at its end. Such results may be interpreted as a participant's positive inclination towards this specific way of conducting psychotherapy in psychodrama at the beginning of the treatment and the participants' satisfaction with these specificities at the end of the treatment. It may be said that the group members were open to encouraging spontaneity and creativity, redefining existing and defining new roles, gaining insights, as well as the "don't tell me, show me" approach of psychodrama. This may be taken as a confirmation of psychodrama's efficiency in the course of treatment.

\subsection{Group participants' expectations and perception of the psychotherapeutic process and outcome, psychotherapeutic factors and psychodrama specificities before and after treatment regarding gender and age}

After analysing expectations and perception of the psychotherapy process and outcome, psychotherapeutic factors and psychodrama specificities before and after treatment in a group as a whole, we were interested in possible differences regarding the participants' gender and age. These were tested using a series of independent samples non-parametric Mann-Whitney U Tests. The results confirm no statistically significant differences either between men and women or between young and middle adults (there were 23 young and 20 middle adults participating). Even though it has been reported that therapeutic potential in a given group may vary due to the clients' age (McLeod and Ryan 1993) or, according to DeLucia-Waack (1996), cultural factors (that may, to a certain extent, also include gender-specific characteristics), our results do not suggest such variations.

\subsection{Participants' expectations and perception of the psychotherapeutic process and outcome, psychotherapeutic factors and psychodrama specificities before and after treatment regarding the participants' diagnoses}

Based on the participants' diagnoses, an analysis was performed before and after treatment of expectations and perception of the psychotherapy process and outcome, psychotherapeutic factors and psychodrama specificities. The differences between the diagnosis-based groups were calculated by using the independent samples nonparametric Kruskal Wallis Test first and the Mann-Whitney U Test later; and this only after the Kruskal Wallis test showed significant difference. The results of these tests alongside group medians are presented in Table 2. It should be noted that the participants diagnosed with psychosis were excluded from the analysis, due to the fact that they would form a group of only two.

Results show that there are significant differences in psychotherapy outcome expectations and perception before and after treatment between the participants with different diagnoses. Namely, when compared to participants of the groups diagnosed with depression or anxiety, participants diagnosed with a personality disorder (borderline personality disorder) report significantly lower expectations and perception of psychotherapy outcomes before and after treatment. Maybe these findings 
Table 2 Medians and differences in expectations and perception of the psychotherapeutic process and outcome, psychotherapeutic factors and psychodrama specificities regarding participants' diagnoses

\begin{tabular}{|c|c|c|c|c|}
\hline & $\begin{array}{l}\text { Depression } \\
\mathrm{Me}\end{array}$ & $\begin{array}{l}\text { Anxiety } \\
\text { Me }\end{array}$ & $\begin{array}{l}\text { Personality } \\
\text { disorder } \\
\text { Me }\end{array}$ & $\begin{array}{l}\text { Kruskal Wallis Test } \\
\text { Mann_-Whitney U Test }\end{array}$ \\
\hline $\begin{array}{l}\text { Treatment expecta- } \\
\text { tions-Process } 1\end{array}$ & 9.11 & 9.00 & 6.94 & $\begin{array}{l}\mathrm{MR}=24.82 / 20.64 / 11.25 \\
p=0.056\end{array}$ \\
\hline $\begin{array}{l}\text { Treatment expecta- } \\
\text { tions-Process } 2\end{array}$ & 9.78 & 9.83 & 8.94 & $\begin{array}{l}\mathrm{MR}=22.62 / 22.19 / 12.83 \\
p=0.183\end{array}$ \\
\hline $\begin{array}{l}\text { Treatment expecta- } \\
\text { tions-Outcome } 1\end{array}$ & 8.25 & 7.13 & 4.50 & $\begin{array}{l}\mathrm{MR}=25.88 / 19.89 / 10.50 \\
p=0.022 \\
\mathrm{P}<\mathrm{D}, \mathrm{P}<\mathrm{A}\end{array}$ \\
\hline $\begin{array}{l}\text { Treatment expecta- } \\
\text { tions-Outcome } 2\end{array}$ & 8.75 & 7.88 & 4.50 & $\begin{array}{l}\mathrm{MR}=25.00 / 20.69 / 10.58 \\
p=0.039 \\
\mathrm{P}<\mathrm{D}, \mathrm{P}<\mathrm{A}\end{array}$ \\
\hline $\begin{array}{l}\text { Yalom's group fac- } \\
\text { tors1 }\end{array}$ & 8.67 & 7.58 & 5.75 & $\begin{array}{l}\mathrm{MR}=26.85 / 19.72 / 8.25 \\
p=0.004 \\
\mathrm{P}<\mathrm{D}, \mathrm{P}<\mathrm{A}\end{array}$ \\
\hline $\begin{array}{l}\text { Yalom's group fac- } \\
\text { tors2 }\end{array}$ & 8.33 & 8.25 & 7.33 & $\begin{array}{l}\mathrm{MR}=23.18 / 21.00 / 14.83 \\
p=0.339\end{array}$ \\
\hline $\begin{array}{l}\text { Psychodrama speci- } \\
\text { ficities1 }\end{array}$ & 7.33 & 7.17 & 6.25 & $\begin{array}{l}\mathrm{MR}=24.18 / 20.64 / 13.08 \\
p=0.146\end{array}$ \\
\hline $\begin{array}{l}\text { Psychodrama speci- } \\
\text { ficities } 2\end{array}$ & 8.00 & 7.92 & 6.92 & $\begin{array}{l}\mathrm{MR}=22.88 / 21.00 / 15.67 \\
p=0.446\end{array}$ \\
\hline
\end{tabular}

Notes: $N_{\text {depression }}=17 ; N_{\text {anxiety }}=18 ; N_{\text {personalitydisorder }}=6$

$M R$ Mean Rank, $P$ group of participants with borderline personality disorder, $D$ group of participants with depression, $A$ group of participants with anxiety, $1=$ assessment before treatment, $2=$ assessment after treatment

can be explained by the fact that individuals diagnosed with borderline personality disorder are characterised by having special difficulties creating and maintaining relationships (Benjamin and Karpiak 2001; Lingiardi et al. 2005). Because of these difficulties, which also interfere with building and maintaining a therapeutic alliance (Havsteen-Franklin et al. 2018), their treatment is especially demanding, which may be reflected in their lower outcome expectations and perception, when compared to individuals diagnosed with depression or anxiety.

Also, it can be noted from the results that expectations regarding psychotherapeutic factors before treatment varied between participants with different diagnoses. Again, participants diagnosed with borderline personality disorder had a significantly lower expectation regarding psychotherapeutic factors than the other two groups. Similar interpretation can be offered here: maybe lower expectations of therapeutic factors at the beginning of the treatment in participants diagnosed with borderline personality disorders are connected to their previous difficulties in interpersonal relationships. Because of that, they assigned lesser value to the therapeutic factors of the group, which inevitably implies a network of (possibly difficult) relationships. 


\subsection{Psychodrama specificities}

Lastly, we tried to have a detailed look into the variability of expectations and perceptions of psychodrama specificities within the group. How did each participant see the specificities of psychodramatic psychotherapy? In order to accomplish this goal, we looked at the participants' assessment of these specificities before and after treatment: how many participants rated each specificity higher at the end of the treatment (and by how many points) than at the beginning (improving the opinion of its therapeutic potential), how many rated it the same and how many (and by how many points) rated it lower (worsening their perception of its therapeutic potential). These results are presented in Table 3, alongside the range of assessments for each psychodrama specificity and the maximum and minimum improvements or worsening.

Results show that the majority (between 20 and 25 members or 46-58\%) of group participants improved the perception of each psychodrama specificity in the course of their treatment. The range of this improvement was highest when new roles are being developed and the "don't tell me, show me" approach is being used (66 and 54 points respectively).

Then, there were participants (between 10 and 15 members or 23-35\%) whose assessment of psychodrama specificities shows they did not change their perception of them. More importantly, there were between three and ten group participants (or 7-23\%) whose perception of psychodrama specificities worsened. Again, the range of such deterioration is highest when assessing the development of new roles in psychodrama and its potential to lead to insights. Maybe, such results are indicative of some participants' disappointment in psychodrama.

It should also be noted that for each psychodrama specificity the participants provided answers distributed along the whole scale, from "not at all" to "very much so"-indicating the variations in their perception of these specificities. The same may be concluded from the analysis of maximal changes in perceptions, which spread from two points less to as far as nine points less-indicating a severe drop in the participant's evaluation of a certain psychodrama specificity.

These results call for further exploration and highlight the importance of detailed observation of each group participant, with regard to their perception of psychodrama specificities. Perhaps this variation can be connected to the variations found in

Table 3 Intragroup variability of participants' expectations and perceptions of psychodrama specificities

\begin{tabular}{lllllll}
\hline $\begin{array}{l}\text { Psychodrama speci- } \\
\text { ficities }\end{array}$ & Improved & Same & Worse & Range & Max & Min \\
\hline Spontaneity & $20(44 \mathrm{pt})$ & 13 & $10(14 \mathrm{pt})$ & $1-10$ & $7 \mathrm{i}, 3 \mathrm{w}$ & $1 \mathrm{i}, 1 \mathrm{w}$ \\
Creativity & $21(37 \mathrm{pt})$ & 12 & $10(16 \mathrm{pt})$ & $1-10$ & $5 \mathrm{i}, 3 \mathrm{w}$ & $1 \mathrm{i}, 1 \mathrm{w}$ \\
Old roles & $22(47 \mathrm{pt})$ & 13 & $8(19 \mathrm{pt})$ & $1-10$ & $5 \mathrm{i}, 5 \mathrm{w}$ & $1 \mathrm{i}, 1 \mathrm{w}$ \\
New roles & $24(66 \mathrm{pt})$ & 10 & $9(30 \mathrm{pt})$ & $1-10$ & $8 \mathrm{i}, 9 \mathrm{w}$ & $1 \mathrm{i}, 1 \mathrm{w}$ \\
Insight & $20(34 \mathrm{pt})$ & 14 & $9(24 \mathrm{pt})$ & $1-10$ & $5 \mathrm{i}, 7 \mathrm{w}$ & $1 \mathrm{i}, 1 \mathrm{w}$ \\
Comparison & $25(54 \mathrm{pt})$ & 15 & $3(6 \mathrm{pt})$ & $1-10$ & $7 \mathrm{i}, 2 \mathrm{w}$ & $1 \mathrm{i}, 2 \mathrm{w}$ \\
\hline
\end{tabular}

Notes: $p t$ points at the questionnaire, $i$ improvement of perception of therapeutic potential, $w$ worsening of perception of therapeutic potential 
the tolerance for different emotion arousal levels explained by Porges (2007). The "window of tolerance" represents an area within which the intensity of the emotion arousal allows an individual to function well (Siegel 1999). Since it is different for every individual and fluctuates within one person, a therapist has to stay alert to properly address it. This is especially true for psychodrama, as its particular value compared to verbal therapy lies in its capability to awaken feelings in group members (Meillo 1991). This may be welcomed as an opportunity for an acutely felt, relived insight that supports treatment, but with the ongoing precaution that it does not become overwhelming.

\section{Conclusion}

In the present article, the expectations and perceptions of the psychotherapy process and outcome, psychotherapeutic factors and psychodrama specificities are presented and analysed in the psychodrama group for adult participants at an outpatient psychiatric clinic. The participants' expectations regarding the psychotherapy process and outcomes are quite high at the beginning of their treatment and rise significantly at its end. This may indicate the meeting of their high expectations in the course of treatment, resulting in therapeutic alliance. Furthermore, the group participants' expectations regarding psychodrama specificities are quite high from the beginning of their treatment, and they significantly increase at its end. This may be interpreted as a participant's positive inclination towards the specific way of conducting psychotherapy through using psychodrama, at the beginning of treatment, and the participants' satisfaction with these specificities at the end of treatment.

Significant differences in psychotherapy outcome expectations before and after treatment and expectations regarding psychotherapeutic factors before treatment between the participants with different diagnoses are compelling and call for further research. A detailed analysis of each psychodrama specificity showed interesting intergroup variabilities.

The importance of the study lies in its attempt to capture the therapeutic process including psychodrama. The results of the study may be used in the framework of psychotherapy and contribute to its further improvement. Since the participants, cared for within a psychiatric clinic, represent an especially vulnerable group, such improvements may be of great value. The questionnaire inquiring into the perception of psychodrama specificities and a detailed analysis of these specificities may be stressed as an innovation in the study, especially for the field of psychodrama. However, the shortcomings of the study, such as the specific characteristics of the sample (the rather small number of participants and their uneven distribution across gender and diagnosis; no control group) should not pass unnoticed. Therefore, the obtained results should be generalised with caution. Since the participants selfassessed the variables, their subjectivity should also be mentioned. The participants, besides psychodrama, also attended other forms of therapy during their treatment in the outpatient clinic and therefore the presented outcomes cannot be solely attributed to the psychodrama group. Such specifications might be the aim of some future studies. It would also be valuable if the data were gathered again after some time 
since the end of the treatment, thus providing information on long-term treatment outcomes.

\section{References}

Ardito, R. B., \& Rabellino, D. (2011). Therapeutic alliance and outcome of psychotherapy: Historical excursus, measurements, and prospects for research. Frontiers in Psychology, 2, 270. https://doi.org/ 10.3389/fpsyg.2011.00270.

Benjamin, L. S., \& Karpiak, C.P. (2001). Personality disorders. Psychotherapy: Theory, Research, \& Practice, 38, 487-491. https://doi.org/10.1037/0033-3204.38.4.487.

Blatner, A. (2000). Foundations of psychodrama. New York: Springer.

Blatner, A. (2007). Morenian approaches: recognising psychodrama's many facets. Journal of Group Psychotherapy, Psychodrama and Sociometry, 59(4), 159-170.

Bordin, E.S. (1979). The generalizability of the psychoanalytic concept of the working alliance. Psychotherapy, 16, 252-260. https://doi.org/10.1037/h0085885.

Clark, A. J. (1993). Interpretation in group counselling: theoretical and operational issues. The Journal for Specialists in Group Work, 18, 174-181. https://doi.org/10.1080/01933929308413752.

Crouch, E. C., Bloch, S., \& Wanlass, J. (1994). Therapeutic factors: Interpersonal and intrapersonal mechanisms. In A. Fuhriman \& G. Burlingame (Eds.), Handbook of group psychotherapy (pp. 269-315). New York: Wiley.

D'Aniello, C., \& Tambling, R.B. (2017). The Effect of Expectations on Intention to Persist in Therapy. The American Journal of Family Therapy, 45(1), 37-50. https://doi.org/10.1080/01926187.2016. 1223568 .

Dayton, T. (1994). The drama within: psychodrama and experiential therapy. Florida: Health Communications.

DeLucia-Waack, J. (1996). Multiculturalism is inherent in all group work. The Journal for Specialists in Group Work, 21, 218-223.

Flowers, J. V. (1987). Client outcome as a function of agreement or disagreement with the modal group perception of curative factors in short-term, structured group psychotherapy. International Journal of Group Psychotherapy, 37, 113-117.

Freud, S. (1913). On the beginning of treatment (Further recommendations on the technique of psychoanalysis I). In J. Strachey (Ed.), (pp. 122-144). London: Hogarth, Standard Edition of the Complete Psychological Works of S. Freud, Volume XII (1911-1913).

Fuhriman, A., Drescher, S., Hanson, E., Henrie, R., \& Rybicki, W. (1986). Refining the measurement of curativeness: an empirical approach. Small Group Behavior, 17, 186-201.

Gillaspy, J. A., Wright, A.R., Campbell, C., Stokes, S., \& Adinoff, B. (2002). Group alliance and cohesion as predictors of drug and alcohol abuse treatment outcomes. Psychotherapy Research, 12(2), 213-229.

Goldberg, F. S., McNiel, D.E., \& Binder, R.L. (1988). Therapeutic factors in two forms of inpatient group psychotherapy: music therapy and verbal therapy. Group, 12(3), 145-156.

Havsteen-Franklin, D., Haeyen, S., Grant, C., \& Karkou, V. (2018). A thematic synthesis of therapeutic actions in arts therapies and their perceived effects in the treatment of people with a diagnosis of Cluster B personality disorder. The Arts in Psychotherapy. https://doi.org/10.1016/j.aip.2018.10.001.

Horvath, A. O., \& Greenberg, L.S. (1989). Development and validation of the working alliance inventory. Journal of Counseling Psychology, 36(2), 223-233.

Horvath, A. O., \& Luborsky, L. (1993). The role of the therapeutic alliance in psychotherapy. Journal of Consulting and Clinical Psychology, 61(4), 561-573.

Johnson, I. H., Torres, J. S., Coleman, V.D., \& Smith, M.C. (1995). Issues and strategies in leading culturally diverse counseling groups. The Journal for Specialists in Group Work, 20, 143-150.

Kail, R. V., \& Cavanaugh, J.C. (2010). Human development—a life-span view. Wadsworth: Belmont.

Kellerman, P.F. (1987). Psychodrama participants' perception of therapeutic factors. Small Group Behavior, 18, 408-419.

Lambert, M. J., \& Barley, D.E. (2001). Research summary on the therapeutic relationship and psychotherapy outcome. Psychotherapy, 38(4), 357-361.

Lingiardi, V., Filippucci, L., \& Baiocco, R. (2005). Therapeutic alliance evaluation in personality disorders psychotherapy. Psychotherapy Research, 15(1-2), 45-53. https://doi.org/10.1080/1050330051233132 7047. 
Luborsky, L. (1976). Helping alliances in psychotherapy: the groundwork for a study of their relationship to its outcome. In J.L. Cleghorn (Ed.), Successful psychotherapy (pp. 92-116). New York: Brunner/ Mazel.

Marcovitz, R. J., \& Smith, J.E. (1983). Patients' perceptions of curative factors in short-term group psychotherapy. International Journal of Group Psychotherapy, 33, 21-39.

McLeod, J., \& Ryan, A. (1993). Therapeutic factors experienced by members of an outpatient therapy group for older women. British Journal of Guidance \& Counselling, 21, 64-72.

Meillo, J. (1991). Issues of milieu therapy: psychodrama as a contribution to the treatment of a case of anorexia nervosa. In P. Holmes \& M. Karp (Eds.), Psychodrama: Inspiration and technique (pp. 137-153). London: Tavistock/Routledge.

Moreno, J. L. (1983). The theatre of spontaneity. Ambler: Beacon House.

Norberg, M.M., Wetterneck, C.T., Sass, D.A., \& Kanter, J.W. (2011). Development and psychometric evaluation of the Milwaukee Psychotherapy Expectations Questionnaire. Journal of Clinical Psychology, 67(6), 574-590. https://doi.org/10.1002/jclp.20781.

Pinsof, W. M., \& Catherall, D.R. (1986). The integrative psychotherapy alliance: family, couple and individual therapy scales. Journal of Marital and Family Therapy, 12, 137-151.

Porges, S. W. (2007). The polyvagal perspective. Biological Psychology, 74(2), 116-143. https://doi.org/ 10.1016/j.biopsycho.2006.06.009.

Prosen, S. (2016). Psychodrama in the group of patients diagnosed with eating disorders. Zeitschrift für Psychodrama und Soziometrie, 15(1), 131-141. https://doi.org/10.1007/s11620-015-0305-x.

Prosen, S., \& Jendričko, T. (2014). Psychodrama Specificities Questionnaire. unpublished material.

Safran, J.D., \& McMain, S. (1990). Therapeutic alliance rupture as therapy event for empirical investigation. Psychotherapy Theory Research \& Practice, 27(2), 154-165.

Siegel, D. J. (1999). The developing mind. New York, London: Guilford.

Strupp, H.H. (2001). Implications of the empirically supported treatment movement for psychoanalysis. Psychoanal. Dialogues, 11, 605-619.

Strupp, H. H., \& Hadley, S. W. (1979). Specific versus non-specific factors in psychotherapy: a controlled study of outcome. Archives in General Psychiatry, 36, 1125-1136.

Yalom, I., \& Leszcz, M. (2005). The theory and practice of group psychotherapy (5th edn.). New York: Basic Books.

Zilcha-Mano, Z., Roose, S.P., Brown, P. J., \& Rutherford, B. R. (2019). Not just nonspecific factors: the roles of alliance and expectancy in treatment, and their neurobiological underpinnings. Frontiers of Behavioral Neuroscience, 12, 293.

Zupančič, M., Komidar, L., \& Levpušček, P. M. (2014). Individuation in Slovene emerging adults: Its associations with demographics, transitional markers, achieved criteria for adulthood, and life satisfaction. Journal of Adolescence, 37(8), 1421-1433. https://doi.org/10.1016/j.adolescence.2014.03.014.

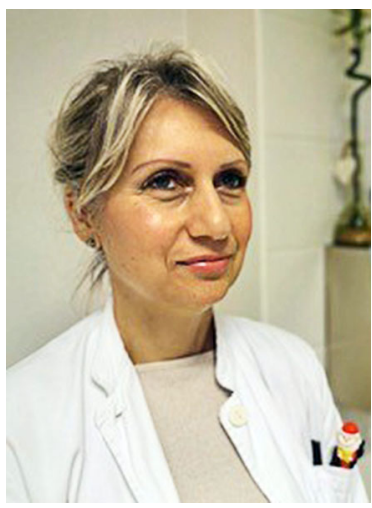

Tihana Jendričko born in 1971, MD, PhD, Assistant Professor, psychiatrist is the Head of the Department of Psychotherapy at the University Psychiatric Hospital Vrapče, Zagreb, Croatia. She completed her training in Integrative Psychotherapy and Moreno's Psychodrama and conducts individual and group psychotherapy in her daily clinical work, as well as in private practice. She teaches psychiatric specialists, nurses, and work therapists at the postgraduate level. An educator, a mentor, and a supervisor of psychiatric residents in psychotherapy as well as psychodrama trainees, she teaches Psychodrama and Sociodrama at the Postgraduate Specialist Study of Creative Therapy. These courses are taught in cooperation with the Academy of Art and Medical School in Osijek, Croatia. She also teaches Social Psychiatry at the Social Work Studies at the Law School, University of Zagreb, as well as Psychiatry as a part of a course in the Propaedeutic of Psychotherapy. Tihana Jendričko is an active member of the Croatian Psychiatric Association, the Croatian Association for Integrative Psychotherapy, the Association of Psychotherapeutic Associations of Croatia, the European Association for Integrative Psychotherapy, the European Association for Psychotherapy, Educational Board of Centre for Psychodrama in Zagreb, and Executive Board of Croatian Chamber of Psychotherapy. 


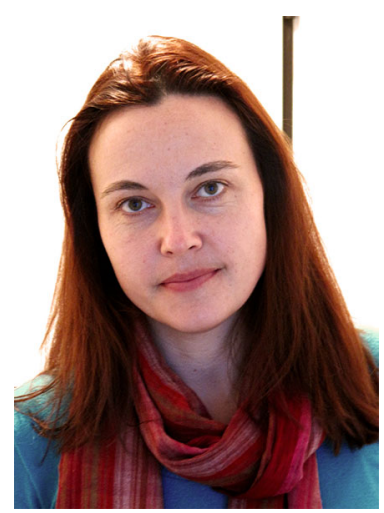

Simona Prosen born in 1972, Assist. Prof. Dr., psychologist and psychodrama psychotherapist.Simona Prosen works at the Faculty of Education, University of Ljubljana, Slovenia, where she teaches developmental psychology. She works psychotherapeutically and as supervisor in her private practice, with groups and individuals. Before she was working at the University Psychiatric Clinic Ljubljana where she conducted therapeutic groups with various groups of patients, the longest with patients with eating disorders and addictions. She is the member of the Educational Board of Centre for Psychodrama in Zagreb and Slovenian Psychodrama Association and participates in psychodrama education in Croatia and Slovenia. She is one of the founding members of the Slovenian Psychodrama Association. She is the member of the FEPTO Research Committee. 